\title{
Vesta's north pole quadrangle Av-1 (Albana): Geologic map and the nature of the south polar basin antipodes
}

\author{
David T. Blewett ${ }^{\mathrm{a}, *}$, Debra L. Buczkowski ${ }^{\mathrm{a}}$, Ottaviano Ruesch ${ }^{\mathrm{b}}$, Jennifer E. Scully ${ }^{\mathrm{c}}$, David P. O’Brien ${ }^{\mathrm{d}}$, \\ Robert Gaskell ${ }^{\mathrm{d}}$, Thomas Roatsch ${ }^{\mathrm{e}}$, Timothy J. Bowling ${ }^{\mathrm{f}}$, Anton Ermakov ${ }^{\mathrm{g}}$, Harald Hiesinger ${ }^{\mathrm{b}}$, \\ David A. Williams ${ }^{\mathrm{h}}$, Carol A. Raymond ${ }^{\mathrm{i}}$, Christopher T. Russell ${ }^{\mathrm{c}}$ \\ a Planetary Exploration Group, Space Department, Johns Hopkins University Applied Physics Laboratory, MS 200-W230, 11100 Johns Hopkins Road, Laurel, MD 20723, USA \\ ${ }^{\mathrm{b}}$ Institut für Planetologie, Westfälische Wilhelms-Universität, Münster, Germany \\ ${ }^{\mathrm{c}}$ University of California, Los Angeles, CA 90095, USA \\ d Planetary Science Institute, Tucson, AZ 85719, USA \\ ${ }^{\text {e }} \mathrm{DLR}$, Berlin, Germany \\ ${ }^{\mathrm{f}}$ Purdue University, West Lafayette, IN 47907, USA \\ ${ }^{\mathrm{g}}$ Massachusetts Institute of Technology, Cambridge, MA 02139, USA \\ ${ }^{\mathrm{h}}$ School of Earth and Space Exploration, Arizona State University, Tempe, AZ 85287, USA \\ i Jet Propulsion Laboratory/Caltech, Pasadena, CA 91109, USA
}

\section{A R T I C L E I N F O}

\section{Article history:}

Received 16 May 2013

Revised 5 March 2014

Accepted 5 March 2014

Available online $\mathrm{xxxx}$

\section{Keywords:}

Asteroid Vesta

Geological processes

Impact processes

\begin{abstract}
A B S T R A C T
As part of systematic global mapping of Vesta using data returned by the Dawn spacecraft, we have produced a geologic map of the north pole quadrangle, Av-1 Albana. Extensive seasonal shadows were present in the north polar region at the time of the Dawn observations, limiting the ability to map morphological features and employ color or spectral data for determination of composition. The major recognizable units present include ancient cratered highlands and younger crater-related units (undivided ejecta, and mass-wasting material on crater floors). The antipode of Vesta's large southern impact basins, Rheasilvia and Veneneia, lie within or near the Av-1 quadrangle. Therefore it is of particular interest to search for evidence of features of the kind that are found at basin antipodes on other planetary bodies. Albedo markings known as lunar swirls are correlated with basin antipodes and the presence of crustal magnetic anomalies on the Moon, but lighting conditions preclude recognition of such albedo features in images of the antipode of Vesta's Rheasilvia basin. "Hilly and lineated terrain," found at the antipodes of large basins on the Moon and Mercury, is not present at the Rheasilvia or Veneneia antipodes. We have identified small-scale linear depressions that may be related to increased fracturing in the Rheasilvia and Veneneia antipodal areas, consistent with impact-induced stresses (Buczkowski, D. et al. [2012b]. Analysis of the large scale troughs on Vesta and correlation to a model of giant impact into a differentiated asteroid. Geol. Soc. of America Annual Meeting. Abstract 152-4; Bowling, T.J. et al. [2013]. J. Geophys. Res. - Planets, 118. http://dx.doi.org/10.1002/jgre.20123). The general high elevation of much of the north polar region could, in part, be a result of uplift caused by the Rheasilvia basin-forming impact, as predicted by numerical modeling (Bowling, T.J. et al. [2013]. J. Geophys. Res. - Planets, 118. http://dx.doi.org/10.1002/jgre.20123). However, stratigraphic and crater size-frequency distribution analysis indicate that the elevated terrain predates the two southern basins and hence is likely a remnant of the ancient vestan crust. The lack of large-scale morphological features at the basin antipodes can be attributed to weakened antipodal constructive interference of seismic waves caused by an oblique impact or by Vesta's non-spherical shape, or by attenuation of seismic waves because of the physical properties of Vesta's interior. A first-order analysis of the Dawn global digital elevation model for Vesta indicates that areas of permanent shadow are unlikely to be present in the vicinity of the north pole.
\end{abstract}

(c) 2014 Elsevier Inc. All rights reserved.

\footnotetext{
* Corresponding author.

E-mail address: david.blewett@jhuapl.edu (D.T. Blewett).
}

\section{Introduction}

The existence of a large impact basin near Vesta's south pole was discovered through imaging with the Hubble Space Telescope 
(Thomas et al., 1997; Binzel et al., 1997; Kattoum and Dombard, 2009). Mapping by the Dawn spacecraft in orbit around Vesta confirmed that the south polar basin, now named Rheasilvia, is $\sim 500 \mathrm{~km}$ in diameter and $\sim 19 \mathrm{~km}$ deep (Jaumann et al., 2012; Schenk et al., 2012; Marchi et al., 2012). The basin's diameter is about $88 \%$ of the length of the asteroid's major axis. Dawn also discovered a second, older, large southern basin (Veneneia, $400 \mathrm{~km}$ diameter). Approximately half of Veneneia was destroyed by the Rheasilvia basin-forming event (Jaumann et al., 2012; Schenk et al., 2012; Marchi et al., 2012). The age of Rheasilvia has been estimated using the observed crater size-frequency distribution and a lunar-like production function to be $\sim 3.53 \mathrm{byr}$ (Schmedemann et al., 2013); a separate estimate obtained by scaling the average Main Belt asteroid size-frequency distribution to vestan crater sizes yields an age of $\sim 1$ byr (Marchi et al., 2012; Schenk et al., 2012). The model ages of Veneneia are $\sim 3.75 \mathrm{Ga}$ (lower limit, Schmedemann et al., 2013) and 2 Ga (Marchi et al., 2012; Schenk et al., 2012).

On other Solar System bodies, unusual features are sometimes found near the antipode (point diametrically opposite) to large impact basins (see summary in Table 1). "Hilly and lineated" material (Murray et al., 1974; Melosh and McKinnon, 1988) located at the antipode of Mercury's Caloris basin may have been formed by converging seismic waves (Schultz and Gault, 1975; Hughes et al., 1977; Lü et al., 2011) or ejecta (Moore et al., 1974) from the Caloris impact. The regions antipodal to Mercury's other large basins (Tolstoj, Beethoven, Rembrandt) have been resurfaced by volcanic plains or by formation of other basins, thus it is not known if hilly and lineated terrain was formed there (Blewett et al., 2010).

Grooved and broken-up terrain like that at the Caloris antipode occurs at the antipodes of the lunar Imbrium, Serenitatis, Orientale, and Crisium basins (Moore et al., 1974; Schultz and Gault, 1975; Stuart-Alexander, 1978; Wilhelms, 1987), suggesting that similar processes accompanied the formation of these basins (Table 1). The South Pole-Aitken (SPA) basin is the largest recognized impact basin on the Moon (e.g., Schultz, 1976; Stuart-Alexander, 1978; Belton et al., 1992), with a diameter of $\sim 2500 \mathrm{~km}$. The SPA antipode lies within the younger Imbrium basin, therefore any hilly and lineated terrain that may have been formed by SPA was destroyed by the Imbrium basin-forming event. However, Schultz and Crawford (2011) used evidence from laboratory impact experiments and numerical hydrocode simulations to conclude that the SPA collision caused extensive antipodal fracturing in the mantle

Table 1

Characteristics of large impact basins on Mercury, the Moon, Mars, and Mimas, with Vesta's large basins Rheasilvia and Veneneia.

\begin{tabular}{|c|c|c|}
\hline Basin name ${ }^{a}$ & Basin diameter, km & Basin diam./target body diam. \\
\hline Caloris [y] & 1550 & 0.32 \\
\hline Rembrandt [ob] & 715 & 0.15 \\
\hline Beethoven [ob] & 625 & 0.13 \\
\hline Tolstoj [ob] & 510 & 0.10 \\
\hline South Pole-Aitken [ob] & 2500 & 0.72 \\
\hline Imbrium [y] & 1160 & 0.33 \\
\hline Orientale [y] & 930 & 0.27 \\
\hline Serenitatis [y] & 920 & 0.26 \\
\hline Crisium [y] & 740 & 0.21 \\
\hline Hellas [ob] & 2300 & 0.34 \\
\hline Herschel [n] & 139 & 0.35 \\
\hline Rheasilvia [n] & 500 & 0.88 \\
\hline Veneneia [n] & 400 & 0.70 \\
\hline
\end{tabular}

a "Hilly and lineated" terrain at antipode: yes, no, obscured by later activity. Table updated from Blewett et al. (2010). Herschel, Rheasilvia and Veneneia, while lacking hilly and lineated antipodal terrain, do possess other, more subtle morphologic features that could be related to antipodal effects, and flood volcanism at the South Pole-Aitken and Hellas antipodes could have been facilitated by fracturing induced by the formation of these basins (see text). and lower crust that provided pathways for later mare volcanism, explaining the nearside-farside asymmetry in the distribution of the maria. Schultz and Crawford (2011) also suggest that a system of nearside structural elements, attributed by others to the proposed Procellarum basin (e.g., Whitaker, 1981), are radial and concentric to the SPA antipode and can be explained by SPA antipodal effects.

On Mars, the Alba Patera shield volcano is antipodal to the center of the $2300 \mathrm{~km}$ diameter Hellas basin. Williams and Greeley (1994) used numerical modeling to show that the Hellas impact was energetic enough to fracture the crust at the Hellas antipode, resulting in potential conduits for later volcanism that formed Alba Patera (Williams and Greeley, 1994; Peterson, 1978). The extensive volcanism related to Alba Patera would have buried any hilly and lineated terrain that may have existed.

Large impact basins have formed on icy satellites of the outer Solar System (e.g., Schenk, 2010; Schenk et al., 2012, 2013). Hilly and lineated type terrain has not been recognized on these bodies. On Mimas, craters in the area antipodal to the Herschel basin are unusually shallow, possibly a result of antipodal focusing of ejecta or seismic energy (Schenk, 2010).

A correlation between areas of magnetized crust, swirl-like albedo anomalies, and basin antipodes is found on the Moon (Lin et al., 1988; Richmond et al., 2005). The creation of an antipodal magnetic anomaly may involve the amplification of existing magnetic fields by the expanding vapor-melt cloud in a large impact (Hood and Artemieva, 2008), or shock effects of converging ejecta (Hood et al., 2013). Lunar swirls (e.g., El-Baz, 1972; Schultz, 1976; Hood and Schubert, 1980; Schultz and Srnka, 1980; Hood and Williams, 1989; Blewett et al., 2011; Garrick-Bethell et al., 2011; Kramer et al., 2011a,b) are high-reflectance markings with diffuse edges and no measurable topographic expression. According to the solar-wind standoff model for lunar swirls (Hood and Schubert, 1980), the presence of a crustal magnetic anomaly leads to deflection of solar-wind ions, thus protecting the surface from the normal lunar space-weathering process that causes darkening and reddening of freshly exposed material (see Hapke, 2001 for a review of the effects and causes of lunar-style space weathering).

It is clear that Vesta's Rheasilvia and Veneneia impacts produced global effects in the form of the Divalia Fossae and Saturnalia Fossae tectonic troughs (Buczkowski et al., 2012a,b; Jaumann et al., 2012; Scully et al., this issue). Thus, an interesting question is whether unusual terrain texture or albedo patches occur at the antipodes of Vesta's large basins. Inspection of Table 1 would lead to a simple prediction that any crater with a diameter greater than $\sim 0.2$ of its target body size should have produced disrupted terrain at the antipode. Bowling et al. $(2012,2013)$ carried out numerical modeling of the Rheasilvia impact and predicted that antipodal focusing of the impact stress wave would cause large extensional radial strains at the antipode, resulting in uplifted topography and deformed terrain (discussed further in Section 4). Also, Buczkowski et al. (2012b) reported that hydrocode modeling of a Rheasilvia-like impact produced large differential stresses at the antipode. Impact modeling by Jutzi and Asphaug (2011) suggested that the formation of the Rheasilvia basin would have deposited ejecta in the northern hemisphere.

The presence or absence of antipodal terrain on Vesta thus will provide clues to the role of gravity and internal structure (e.g., seismic velocity, porosity, crust-mantle density contrast, and core size/strength) in the formation of basin-related units. Identification of swirl-like albedo or color anomalies near the antipodes of Vesta's large basins could imply that (1) an antipodal magnetization process (Hood and Artemieva, 2008; Hood et al., 2013) took place and produced a crustal magnetic anomaly, and (2) that the solar wind contributes to space-weathering on Vesta, as it does on the Moon and S-type asteroids. 
In this paper we present a description of Vesta's north polar quadrangle (covering $65-90^{\circ} \mathrm{N}$ latitude), designated Av-1 and named for the prominent crater Albana. We assess the region antipodal to the Rheasilvia and Veneneia basins for the presence of features of the type that have been found at basin antipodes on other planetary bodies or predicted by modeling experiments. We discuss the geologic map of the Av-1 quadrangle that was prepared as part of systematic global mapping (Williams et al., this issue). The paper by Williams et al. (this issue) reviews the global geology of the asteroid, presents the goals of the geologic mapping effort for Vesta, and covers the methodologies used for the mapping. Maps of the other quadrangles in the northern hemisphere are presented by Ruesch et al. (this issue) and Scully et al. (this issue), and a global geologic map of Vesta has been published by Yingst et al. (in press).

\section{Data}

Vesta's rotation axis makes an angle of $29^{\circ}$ with respect to the plane of its orbit around the Sun. Dawn entered Vesta orbit on July 16, 2011 (Russell et al., 2004, 2012), in northern winter. Latitudes above $\sim 60^{\circ} \mathrm{N}$ were not illuminated by the Sun during the initial orbital imaging campaign, though more of the region moved out of shadow as the mission progressed. The point at $90^{\circ} \mathrm{N}$ was captured during Dawn's second High Altitude Mapping Orbit (HAMO2, June 15 to July 25, 2012), with much of the surrounding area remaining in shadow. Additional images at lower spatial resolution were obtained during the spacecraft's departure from Vesta (July 26 to August 26, 2012). The total time that Dawn spent at Vesta represents about $31 \%$ of a Vesta year.

Geologic mapping was carried out using mosaics (Roatsch et al. 2012, 2013) of broadband "clear" filter images from the Dawn Framing Cameras (FC) (Sierks et al., 2011; Reddy et al., 2012a) and topographic maps constructed with a stereophotoclinometric technique (e.g., Gaskell et al., 2008) and with stereogrammetry (Preusker et al., 2012). The resolution of the digital elevation model (DEM) is 64 pixels per degree, with an estimated $1-\sigma$ height uncertainty of $8 \mathrm{~m}$. The extensive shadows and large solar illumination angles that are inevitable at high latitudes make FC multispectral images and hyperspectral imaging from the Visible and Infrared (VIR) imaging spectrometer (e.g., De Sanctis et al., 2012a) of limited use in distinguishing color or compositional differences in Av-1.

The maps and discussion presented here use the Dawn team's preferred coordinate system, called the "Claudia system" (Li, 2012; Roatsch et al., 2012; supplemental material of Russell et al., 2012), which is different from the system used by the NASA Planetary Data System for Vesta data (Archinal et al., 2011). Positive longitudes discussed in this paper are, at the time of writing, offset by $150^{\circ}$ from the PDS system, in the sense that longitude $=($ PDS longitude $)-150^{\circ}$. Note that both the Dawn team preferred system and the PDS system use Claudia crater as the reference point for defining longitude. Further information on the Vesta coordinate system and its usage in the work of the Dawn science team is given by Williams et al. (this issue).

Fig. 1 shows the north polar HAMO mosaic $(\sim 70 \mathrm{~m} /$ pixel $)$ used as the mapping base. Fig. 2 presents a close-up of the center of the mosaic in Fig. 1, along with a lower-resolution mosaic composed of images with different lighting. The HAMO mosaic base was supplemented by referring to higher-spatial-resolution images from the Low Altitude Mapping orbit (LAMO, $20 \mathrm{~m} /$ pixel) where available. Fig. 3a is an image of the DEM for the northern hemisphere. A close-up of the DEM for the Av-1 quadrangle is shown in Fig. $3 \mathrm{~b}$. The north pole quadrangle is surrounded by quadrangles Av-2 (Bellicia, Ruesch et al., this issue), Av-3 (Caparronia, Scully et al., this issue), Av-4 (Domitia, Scully et al., this issue), and Av-5 (Floronia, Ruesch et al., this issue).

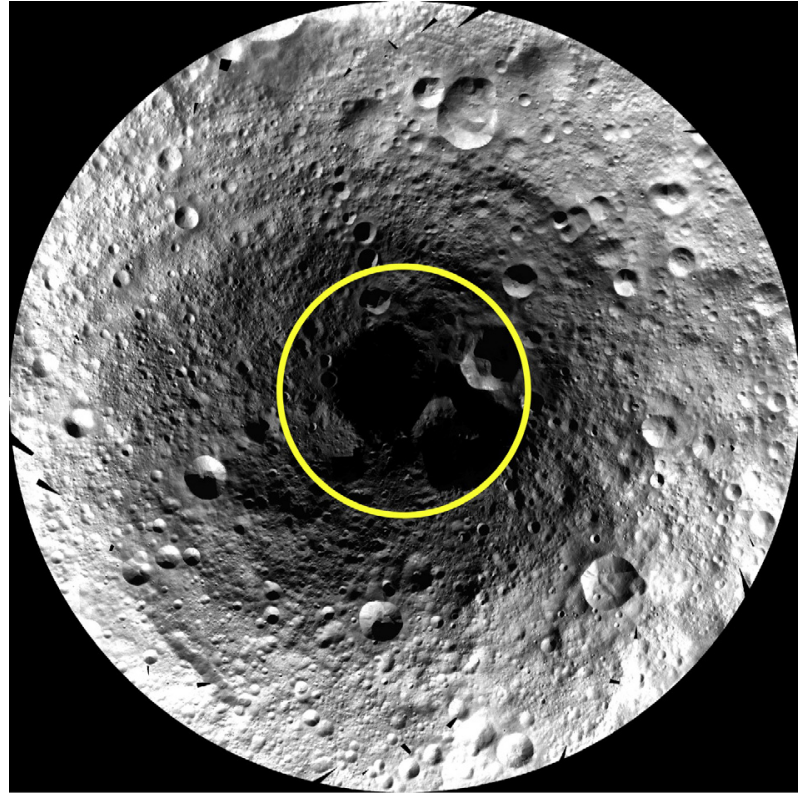

Fig. 1. Mosaic of Vesta's north polar region used as the base for geologic mapping. The image covers the area $20^{\circ}-90^{\circ} \mathrm{N}$ and is in polar stereographic projection. The north pole quadrangle (Av-1, Albana) extends from $65^{\circ} \mathrm{N}$ to the pole and is enclosed by the circle. The mosaic was constructed at $70 \mathrm{~m} /$ pixel and is oriented with $0^{\circ}$ longitude at the bottom. The longitude references used in this paper are in the Claudia system (Li, 2012; supplemental material of Russell et al., 2012).

The center of the Rheasilvia basin is located at $75^{\circ} \mathrm{S}, 301^{\circ} \mathrm{E}$ (Schenk et al., 2012; P. Schenk, personal communication, 2013). Thus, the antipode lies at $75^{\circ} \mathrm{N}, 121^{\circ} \mathrm{E}$. The center of Veneneia $\left(52^{\circ} \mathrm{S}, 170^{\circ} \mathrm{E}-\right.$ Schenk et al., 2012$)$ places the antipode at $52^{\circ} \mathrm{N}$, $350^{\circ} \mathrm{E}$. The antipodes of the Rheasilvia and Veneneia basins are marked on the topographic map, Fig. 3. The Veneneia antipode (Fig. 3c) falls within the Av-5 quadrangle.

The presence of permanent shadows in the polar regions of airless Solar System bodies is of interest because such locations may harbor accumulations of cold-trapped volatile compounds. Stubbs and Wang (2012) performed an extensive study of illumination and thermal conditions on Vesta using the pre-Dawn DEM derived from Hubble Space Telescope images. The Hubble DEM (Thomas et al., 1997 ) is of low resolution $\left(5^{\circ} \times 5^{\circ}\right.$, or about $22 \mathrm{~km}$ at the equator). Stubbs and Wang (2012) did not find any areas of permanent shadow. This is not surprising, because Vesta's obliquity $\left(29^{\circ}\right)$ is much greater than that of bodies like the Moon $\left(1.5^{\circ}\right)$ and Mercury $\left(2.0^{\circ}\right)$ where permanent polar shadow has been documented. However, because the inherent resolution of the Hubble DEM permitted only topographic features larger than $\sim 100 \mathrm{~km}$ to be resolved, those workers noted that permanently shadowed regions could exist.

An updated Vesta thermal model at the level of detail conducted by Stubbs and Wang (2012) is beyond the scope of this paper. However, we performed a first-order search for permanent shadow in the north polar region using the Gaskell global DEM for Vesta. The DEM was displayed in the Small Body Mapping Tool (Kahn et al., 2011), with the surface of the asteroid rendered by $3.146 \times 10^{6}$ plates. The solar illumination was set to be perpendicular to the surface at a latitude of $29^{\circ} \mathrm{N}$, corresponding to the conditions at the peak of northern summer. The longitude of the illumination was varied in $10^{\circ}$ steps from $0^{\circ}$ to $350^{\circ} \mathrm{E}$, representing the daily change as Vesta rotates on its axis. In this exercise, no DEM elements were found to remain in darkness throughout a vestan day. Of course, the Dawn-derived DEM lacks data in areas that were in seasonal shadow during the mapping mission (cf., Fig. 3b), and it is possible, though unlikely, that spots of low elevation within those areas could experience lengthy or permanent shadowing. 

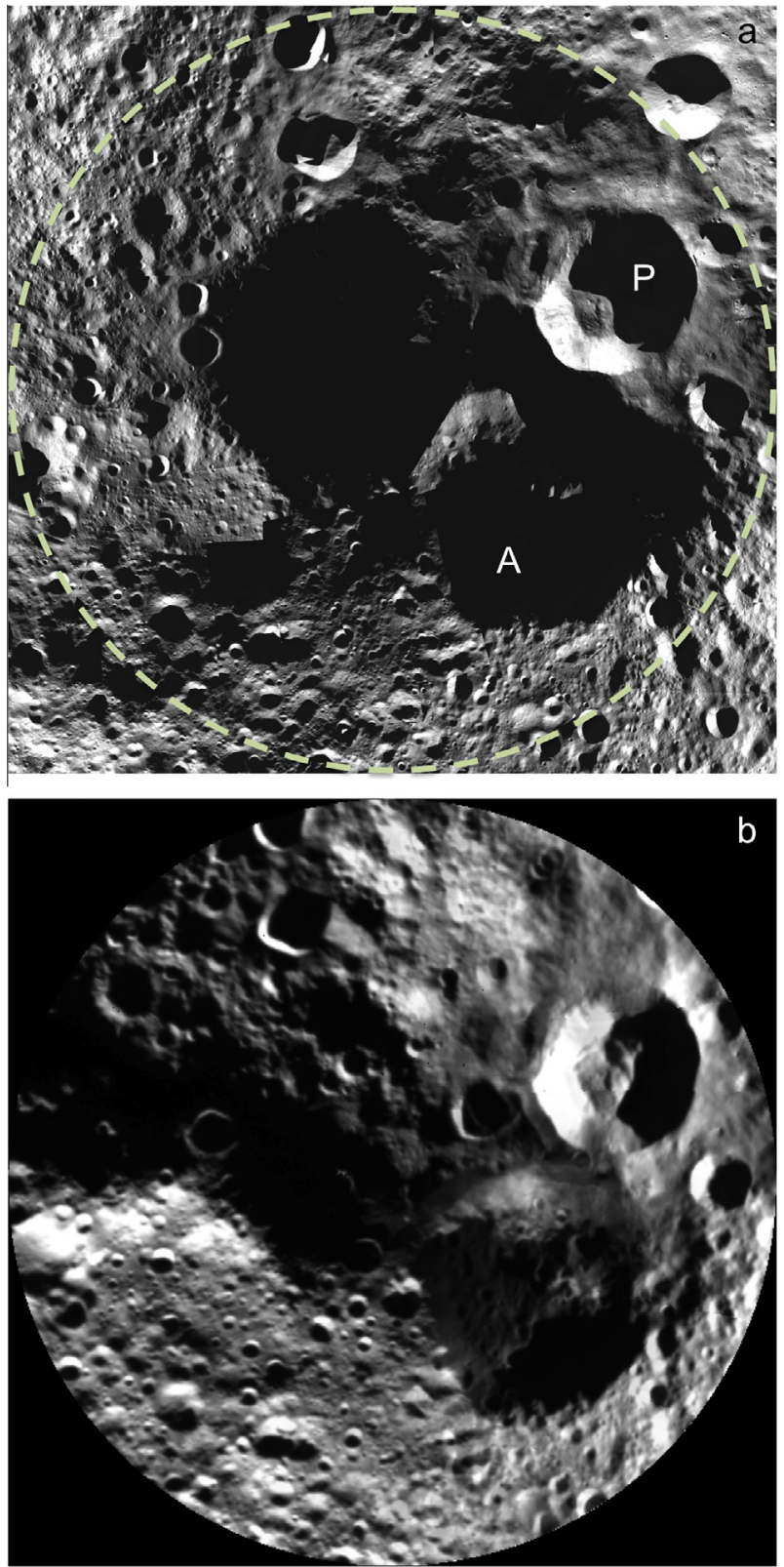

Fig. 2. Mosaics of FC images covering $\sim 60^{\circ} \mathrm{N}$ to the north pole. (a) Closer view of a portion of the mosaic in Fig. 1. Dashed line is at $60^{\circ} \mathrm{N}$. The relatively fresh crater labeled "P" is Pomponia, $63 \mathrm{~km}$ in diameter. Albana ("A", $96 \mathrm{~km}$ diameter) is more degraded. (b) Lower-resolution mosaic from earlier in the mission constructed from images with different illumination than the mosaic in (a).

\section{The geologic map of Av-1}

Fig. 4a is the geologic map of the Av-1 Albana north pole quadrangle, with the map legend in Fig. 4b. Fig. 4c shows all mapped craters in the quadrangle, including those smaller than $6 \mathrm{~km}$ diameter which were omitted from the geologic map (Fig. 4a) for clarity. In this section we give the description of material units for the map, followed by subsections on the major impact craters and cratered highlands of Av-1.

\subsection{Description of material units}

Cratered highlands (ch). Description: Heavily cratered terrain dominating the north polar region. Unit has an intermediate albedo in monochrome FC images. Interpretation: Cratered terrain may be a preserved section of ancient crustal materials or material uplifted by stresses induced by large basin impacts, producing a topographic high.

Undivided crater ejecta material (uc). Description: Unit characterized by a smooth, slightly hummocky surface that surrounds Pomponia and several other craters in Av- 1 . The material appears to blanket and subdue the underlying topography. Interpretation: Continuous ejecta deposited by impact cratering.

Crater interior material (ci). Description: Forms deposits along the bases of steep slopes or crater walls. Displays lobate margins and hummocky or smooth surfaces. Morphologies include sequences of benches separated by crescent-shaped cliffs or scarps beginning at the top of a slope (slump), lobate or fan-shaped, smooth-textured deposits, and irregular hummocky deposits. Interpretation: Mass-wasting in the form of debris fall, slump, or slide through slope failure caused by processes including seismic shaking associated with impact crater formation or slope failure due to overburden.

\subsection{Major impact craters}

The quadrangle is dominated by two large impact craters, Albana and Pomponia (Fig. 2). Albana has a diameter of approximately $96 \mathrm{~km}$ and does not have identifiable ejecta deposits. The crater rim is rounded, and the walls and floor are heavily cratered. These characteristics are consistent with Albana being one of the oldest craters in the Av-1 quadrangle. We have estimated Albana's maximum depth of excavation, following the procedure summarized by Ernst et al. (2010). The maximum depth of excavation is taken to be 0.1 times the transient crater diameter $\left(D_{t c}\right)$. The relationship between $D_{t c}$ and the observed final rim-to-rim diameter $\left(D_{r}\right)$ is in the form of a power law: $D_{t c}=C\left(D_{r}\right)^{k}$, where the constants $C$ and $k$ have been derived by several workers, including Croft (1985) and Holsapple (1993); refer to Table 1 of Ernst et al. (2010) for the specific values. The constant $C$ is a function of the size at which the simple-to-complex crater transition $\left(D_{t r}\right)$ occurs on the body of interest. We assign Vesta's value of $D_{t r}$ to be $28 \mathrm{~km}$, as determined by Schenk et al. (2013). Albana, with $D_{r}=96 \mathrm{~km}$, is found to have a maximum depth of excavation of $\sim 7 \mathrm{~km}$ (Holsapple) to $8 \mathrm{~km}$ (Croft). Crustal thickness mapping of Vesta, based on gravity and shape models (Ermakov et al., 2014), indicates that the crust within the Av-1 quadrangle ranges in thickness from $\sim 20$ to $40 \mathrm{~km}$. Therefore Albana formed well within the crust and is not expected to have exposed material from the lower crust or upper mantle.

Pomponia, $\sim 63 \mathrm{~km}$ in diameter, is morphologically fresh. It has a sharp rim and mappable ejecta deposits (Fig. 4a). The crater formed on a pre-existing slope, the rim of Albana, leading to interior slumping from Pomponia's up-slope side onto its floor. The slump deposit is mapped here as crater interior material (unit $c i$ ). Such effects of impact into a sloping target are common among craters on Vesta (Jaumann et al., 2012; Krohn et al., 2014).

The ejecta of Pomponia is smooth and continuously blankets and subdues the surroundings from the rim to a distance of roughly one crater diameter. The ejecta is mapped as undivided crater ejecta material, unit $u c$. The ejecta extends south into the adjacent Av-3 quadrangle (Caparronia, Scully et al., this issue; see also Ruesch et al., this issue).

The northern wall of Pomponia has high- and low-albedo streaks of material moving downslope. The dark material could have originally resided at depth in the target area, or it could be low-reflectance material delivered by the impacting object. Using the procedure described above for Albana, the maximum depth of excavation calculated for Pomponia is $\sim 5 \mathrm{~km}$. Several lines of evidence indicate that dark material found locally on Vesta and also mixed globally into the regolith is likely to have originated 


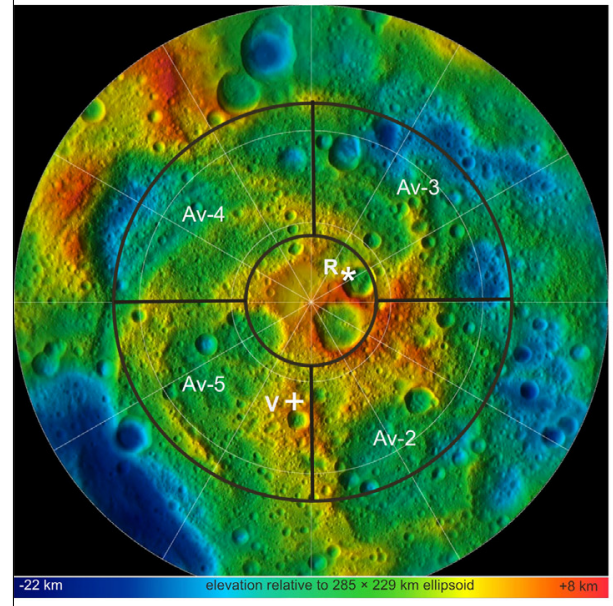

(a)

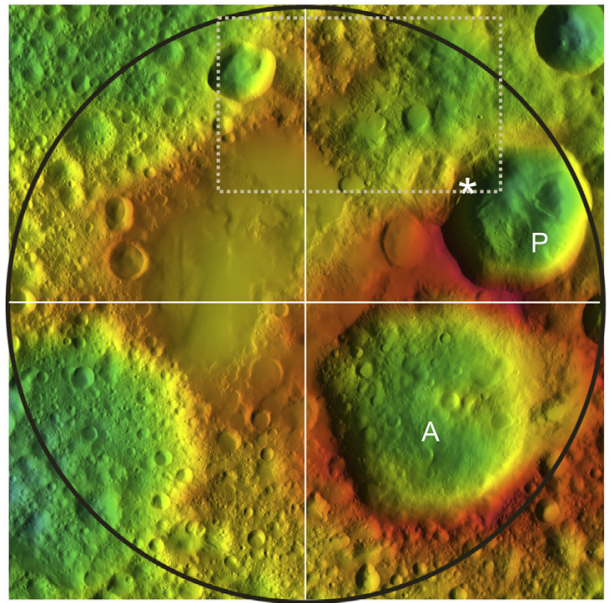

(b)

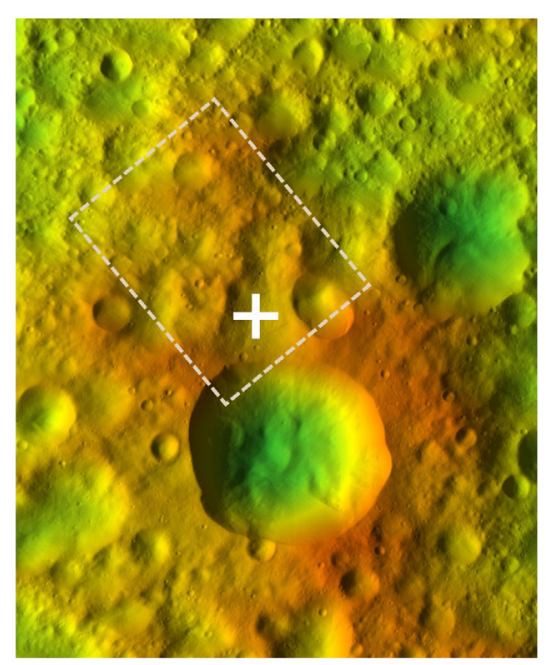

(c)

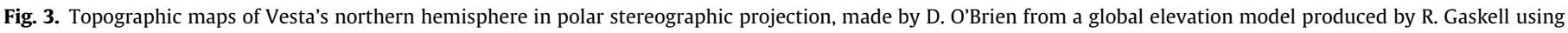

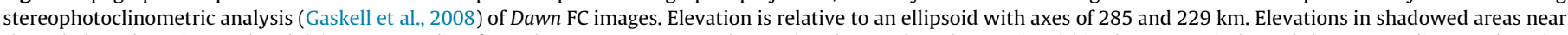

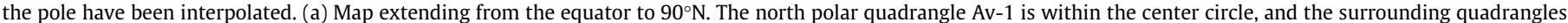

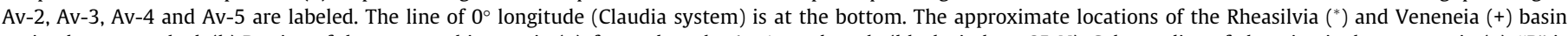

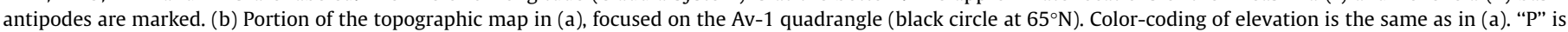

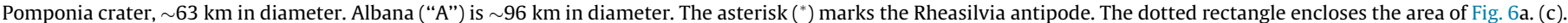

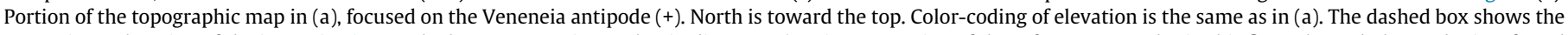

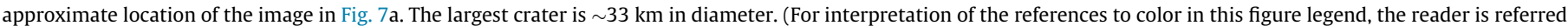
to the web version of this article.)

from relatively low-speed impacts by bodies with a composition similar to that of carbonaceous chondrite meteorites (McCord et al., 2012; Pieters et al., 2012; Reddy et al., 2012b; De Sanctis et al., 2012b; Prettyman et al., 2012). Ruesch et al. (this issue) performed measurements of crater size-frequency distributions for surfaces in Vesta's northern hemisphere including the ejecta of Pomponia; they found an absolute model age for Pomponia of $\sim 370 \mathrm{Ma}$, assuming the chronology and crater production function of Schmedemann et al. (2013). Ruesch et al. (this issue) observed differences between the crater size-frequency distribution measurement of Pomponia and the scaled Main Belt production function of Marchi et al. (2012). Although these differences prevented the determination of an absolute model age for Pomponia crater, the production and chronology functions of Marchi et al. (2012) indicate an older age than the absolute model age obtained with the Schmedemann et al. (2013) chronology and production function.
Within the Av-1 quadrangle, several craters in the $\sim 10-20 \mathrm{~km}$ diameter size range appear to be relatively young, exhibiting sharp rims and smooth continuous ejecta deposits mapped as unit $u c$. One of these craters, located at $\sim 70^{\circ} \mathrm{N}, 195^{\circ} \mathrm{E}$ and named Africana, contains a mounded floor that has been mapped as crater interior material, unit ci, interpreted as a mass-wasting deposit (Fig. 4a).

An arcuate scarp is present along part of the border between quadrangles Av-1 and Av-5, spanning $\sim 270-330^{\circ} \mathrm{E}$ longitude (Figs. 2b and 3). We have mapped this as the degraded partial rim of an impact crater (Fig. 4a) that would have had an original diameter of $\sim 100-120 \mathrm{~km}$. This impact structure corresponds to the "Albana-Mamilia basin" of Ruesch et al. (this issue). The portion of the rim that extended south into quadrangle Av-5 is even more heavily eroded, presumably destroyed by later impacts.

The sector around the north pole from $\sim 180^{\circ}$ to $300^{\circ} \mathrm{E}$ longitude suffers from poor illumination in the available images. This is an area of slightly low elevation (Fig. 3), but it is not clear from 
(a)

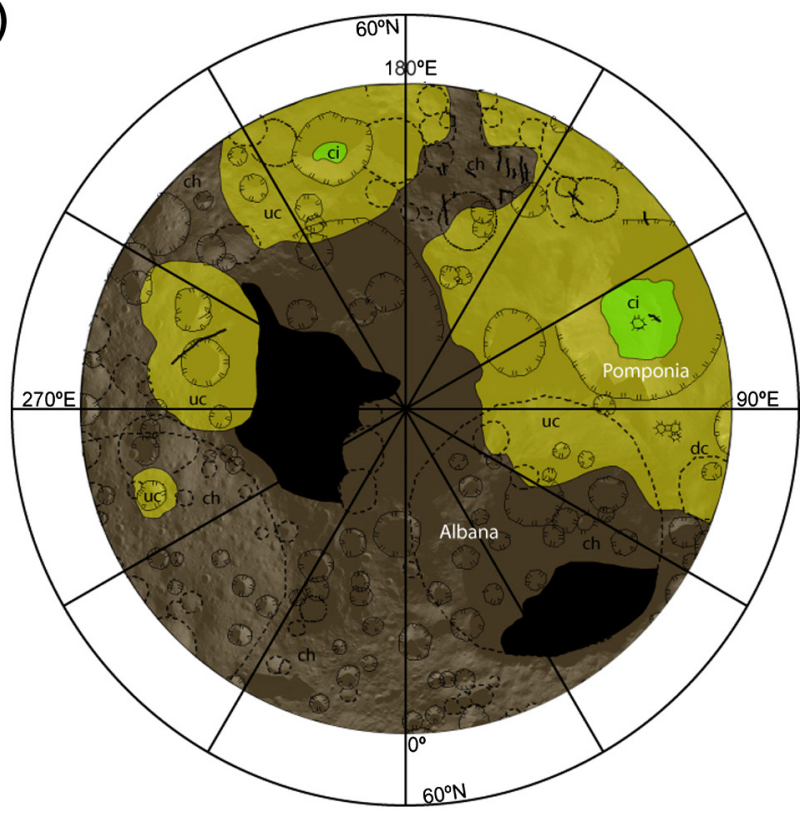

(b)

\section{Geologic Units

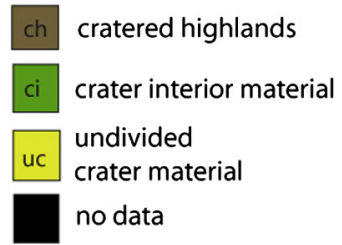

Linear Features

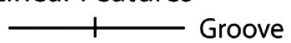

(c)

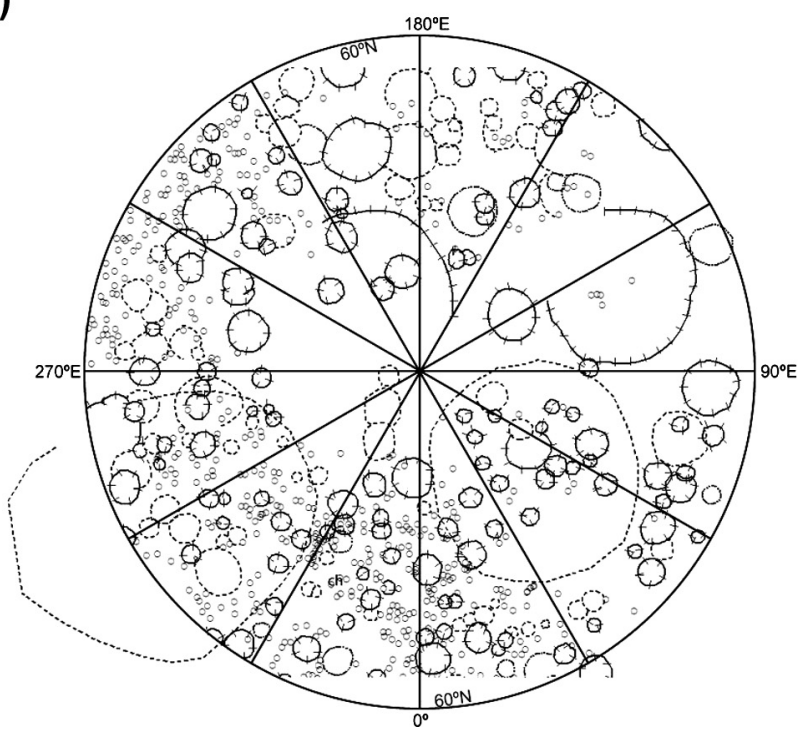

Fig. 4. (a) Geologic map of Vesta's north pole quadrangle, Av-1 Albana. This map includes impact craters larger than $\sim 6 \mathrm{~km}$ in diameter. The map legend is figure (b). Solid black areas were not mapped because of the limitations of the image base and topographic data. Unit boundaries are approximate and gradational. A map with the locations of all identified craters, including those smaller than $6 \mathrm{~km}$, is in (c). (b) Legend for the Av-1 Albana geologic map shown in (a). (c) Map with the locations of all identified craters in the Av-1 quadrangle, including those smaller than $\sim 6 \mathrm{~km}$ diameter that were omitted from (a) to reduce clutter. available images and topographic maps whether a degraded impact structure may be present.

\subsection{Cratered highlands}

Apart from the fresh craters and their deposits, the majority of the illuminated portion of Av- 1 consists of cratered highlands (unit $c h$ ). The cratered highlands unit is the oldest recognizable unit and is overlain by all other units. The cratered highlands in Av-1 correspond to the unit of the same name found farther south, e.g., in Vesta's equatorial quadrangles. The cratered highlands have the highest density of impact craters on Vesta, suggesting it represents the ancient crust (Schmedemann et al., 2013; see also the discussion of crater size-frequency distribution measurements on northern hemisphere exposures of unit ch by Ruesch et al., this issue). In areas of Vesta where the cratered highlands are clearly cut by the Saturnalia Fossa troughs, the unit is referred to as the Saturnalia Fossae Formation (Yingst et al., in press). Structural analysis of the Saturnalia group of fossae suggests that they were formed as a consequence of tectonism induced by the Veneneia basin-forming impact (Buczkowski et al., 2012a; Jaumann et al., 2012; Scully et al., this issue).

\section{Evaluating the presence of Rheasilvia or Veneneia antipodal features}

\subsection{Topographic and structural features}

The topography in quadrangles Av-1 and Av-2 is generally high (Fig. 3). Bowling et al. (2013) have performed numerical modeling of the Rheasilvia impact. They describe two major processes that could produce uplifted topography at the antipode. The first is spalling of material upwards from the surface at the impact antipode. When this material settles back, an increase in void space is expected, contributing to an increased surface elevation. Second, dilation of mantle and crustal materials caused by high strains in response to the impact stress waves can produce an increase in volume. The component of volume increase in the radial direction corresponds to an increase in the elevation of the surface. The degree of antipodal uplift is dependent on factors including the porosity of the mantle and the strength of the core. Hence the observed topography of the area antipodal to Rheasilvia (Fig. 3), in concert with geophysical models of Vesta's interior (e.g., Raymond et al., 2013) may help to further constrain the parameters used in studies such as that of Bowling et al. (2013).

Several observations regarding the nature of the high topography in the northern quadrangle can be made. First, Ruesch et al. (this issue) carried out stratigraphic and crater size-frequency distribution studies of units in Vesta's northern hemisphere. Those workers noted that the high-elevation portions of the north polar area (unit $c h$ ) are cut by very old ruined basins. Second, dilation of the mantle and crust sufficient to produce uplift of $\sim 10 \mathrm{~km}$ would be expected to have a noticeable effect on the gravitational field. However, the Bouguer map of Ermakov et al. (2014) does not reveal strong negative anomalies in the area of the southern basin antipodes. Thus, the elevated terrain most likely represents preexisting topography that predates Rheasilvia and Veneneia rather than material that was uplifted to a great extent as a result of basin-forming impacts. As discussed by Bowling et al. (2013), their modeling indicates that with the mantle porosity of $5 \%$ inferred from Dawn measurements (Russell et al., 2012) the impact stress wave is weakened to the extent that substantial uplift is not induced at the antipode. 


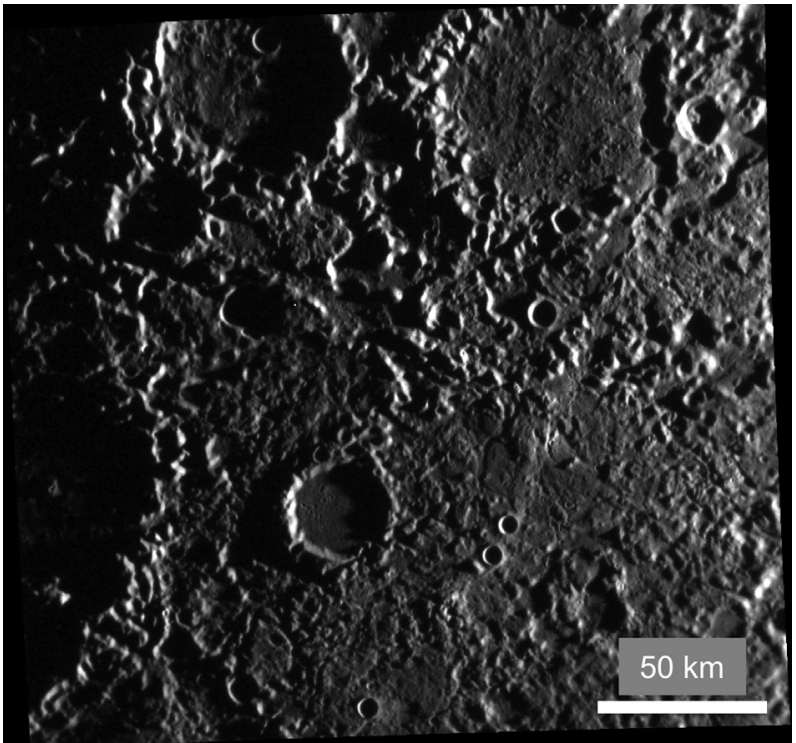

Fig. 5. "Hilly and lineated" terrain (Murray et al., 1974) in the vicinity of the Caloris basin antipode, Mercury. The rims of large craters are cut by distinctive grooves, and intercrater material is broken up into small hills. MESSENGER image EN0220756231M, centered at $29.9^{\circ} \mathrm{S}, 342.1^{\circ} \mathrm{E}$.

The hilly and lineated terrain found on Mercury at the antipode of the Caloris impact basin (Fig. 5) is characterized by a disrupted surface that has been broken up into hills $5-10 \mathrm{~km}$ wide and $\sim 0.1-$ $2 \mathrm{~km}$ high (Murray et al., 1974; Melosh and McKinnon, 1988). No similar patterns are apparent in the images available for the areas antipodal to Vesta's large Rheasilvia or Veneneia basins. The location of the post-Rheasilvia crater Pomponia coincides with the Rheasilvia antipode (Fig. 3), and therefore Pomponia and its ejecta could have obscured hilly and lineated-style terrain that may have been present.

However, we have identified small-scale linear features that could hint at the presence of a degree of fracturing at depth near the Rheasilvia antipode. These features are shown in Fig. 6. The features that we propose may be tracers of antipodal fracturing consist of linear depressions $\sim 250 \mathrm{~m}$ to $\sim 1 \mathrm{~km}$ wide with lengths ranging from $\sim 1$ to $\sim 10 \mathrm{~km}$. These features could represent grooves or surface fractures, or may form by drainage of regolith into extensional fractures that do not reach the surface. We note that grooves are found around some larger vestan craters, likely formed by ejecta sculpting or secondary crater-chain impacts. However, the proposed antipodal fracture-related structural elements are not clearly radial or circumferential to any of the surrounding young impact craters (e.g., Pomponia), and appear to be covered by Pomponia ejecta (Fig. 6). Two independent numerical simulations of the Rheasilvia impact (Buczkowski et al., 2012b; Bowling et al., 2013) both predict large stresses at the antipode. In addition, Bowling et al. (2013) performed crater size-frequency analysis for a portion of Vesta's north polar region, and concluded that an observed deficit of small craters ( $\sim 500 \mathrm{~m}$ to a few kilometers in diameter) could be explained by erasure or degradation produced by Rheasilvia seismic effects. Thus it is plausible that the linear depressions we have identified are a manifestation of fracturing induced by stresses from the Rheasilvia event. Similar small-scale linear features occur in quadrangle Av-5, in the vicinity of the Veneneia antipode (Fig. 7, see also Fig. 3c).

Given the large size of the Rheasilvia and Veneneia basins in relation to Vesta's diameter (Table 1), it is perhaps surprising that antipodal modification of a greater magnitude than the small lineations or degradation of small craters described in the previous paragraph did not take place. As stated above, it is possible that the
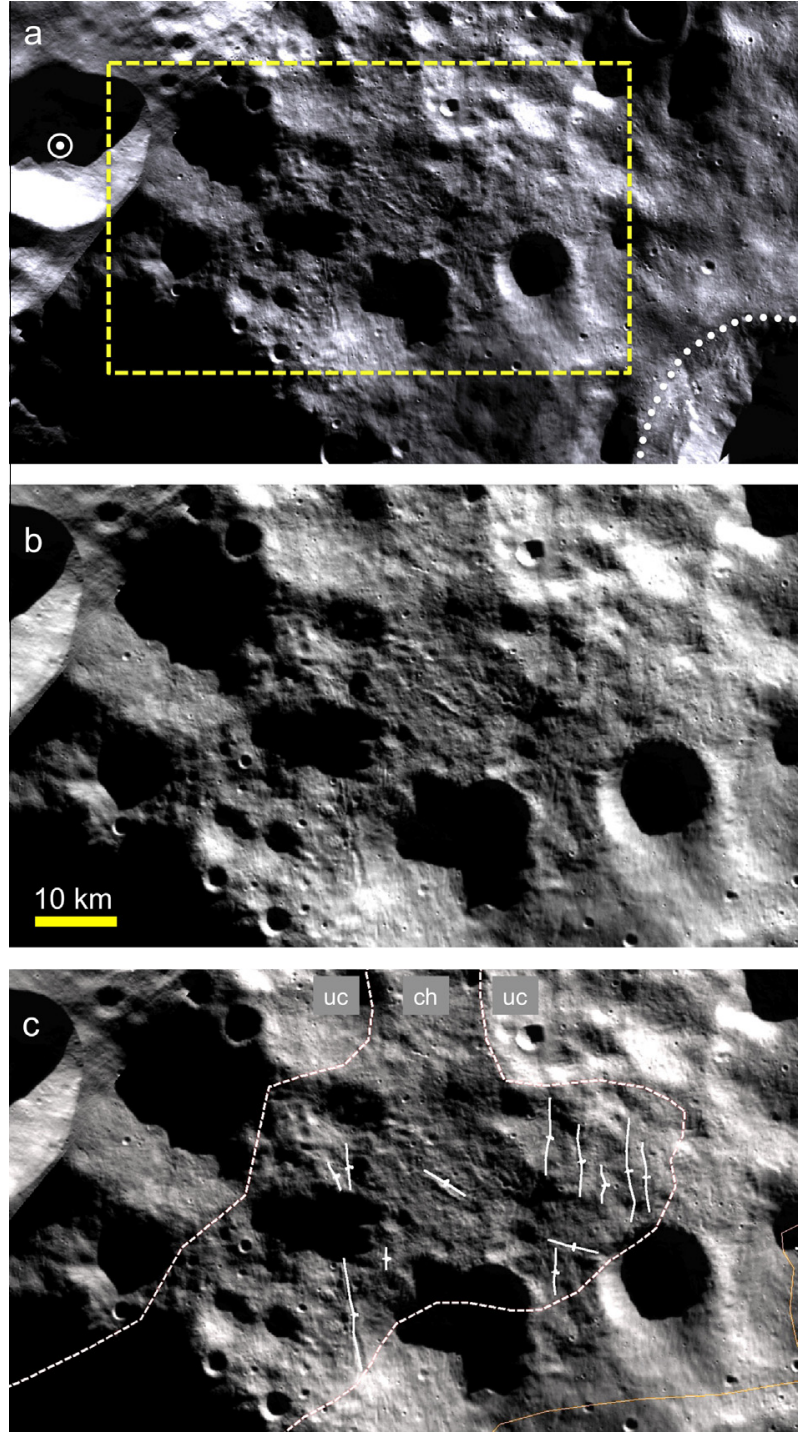

Fig. 6. Terrain exhibiting linear depressions that may be indicative of enhanced fracturing near the Rheasilvia antipode. Refer to Fig. $3 \mathrm{~b}$ for the location of this area in the north polar region DEM. (a) Context image centered at $\sim 69.5^{\circ} \mathrm{N}, 159^{\circ} \mathrm{E}$ indicating type location of the fractured terrain. North is toward the bottom. The dashed box encloses the area shown in (b and c). The dot within a circle marks the center of Africana crater $\left(\sim 70^{\circ} \mathrm{N}, 195^{\circ} \mathrm{E}\right)$, which has mass-wasting material (unit $c i$ ) on its floor (cf., Figs. 2 and 4a). The dotted line is the rim of Pomponia crater. The geometrical antipode of the Rheasilvia basin is near the lower right corner of the image (cf. Fig. 3b). (b) Higher-resolution view of the area within the dashed box shown in (a). (c) Same image as (b), with mapped unit boundaries and structural elements. White line segments with bars are the linear depressions proposed to relate to Rheasilvia antipodal fractures. The dashed line is the approximate boundary of the undivided crater ejecta (unit $u c$, cf. Fig. 4a). The other map unit present in the scene is the cratered highlands $(c h)$. The images are taken from within the HAMO mosaic shown in Fig. 1.

formation of Pomponia obscured some antipodal features that resulted from the Rheasilvia impact. There are, however, several factors that could have inhibited the formation of large antipodal features in the first place.

First, a non-vertical impact or non-spherical shape of the target body can lead to unequal ray paths and hence to delayed or advanced arrival of seismic energy at the antipode. The impact models of both Buczkowski et al. (2012b) and Bowling et al. (2013) were two-dimensional, that is, they simulated a vertical impact onto a spherically symmetric Vesta. Three-dimensional (3-D) simulations that could allow for non-vertical impacts or oblate targets are far more computationally intensive. Analysis of the fossil shape 

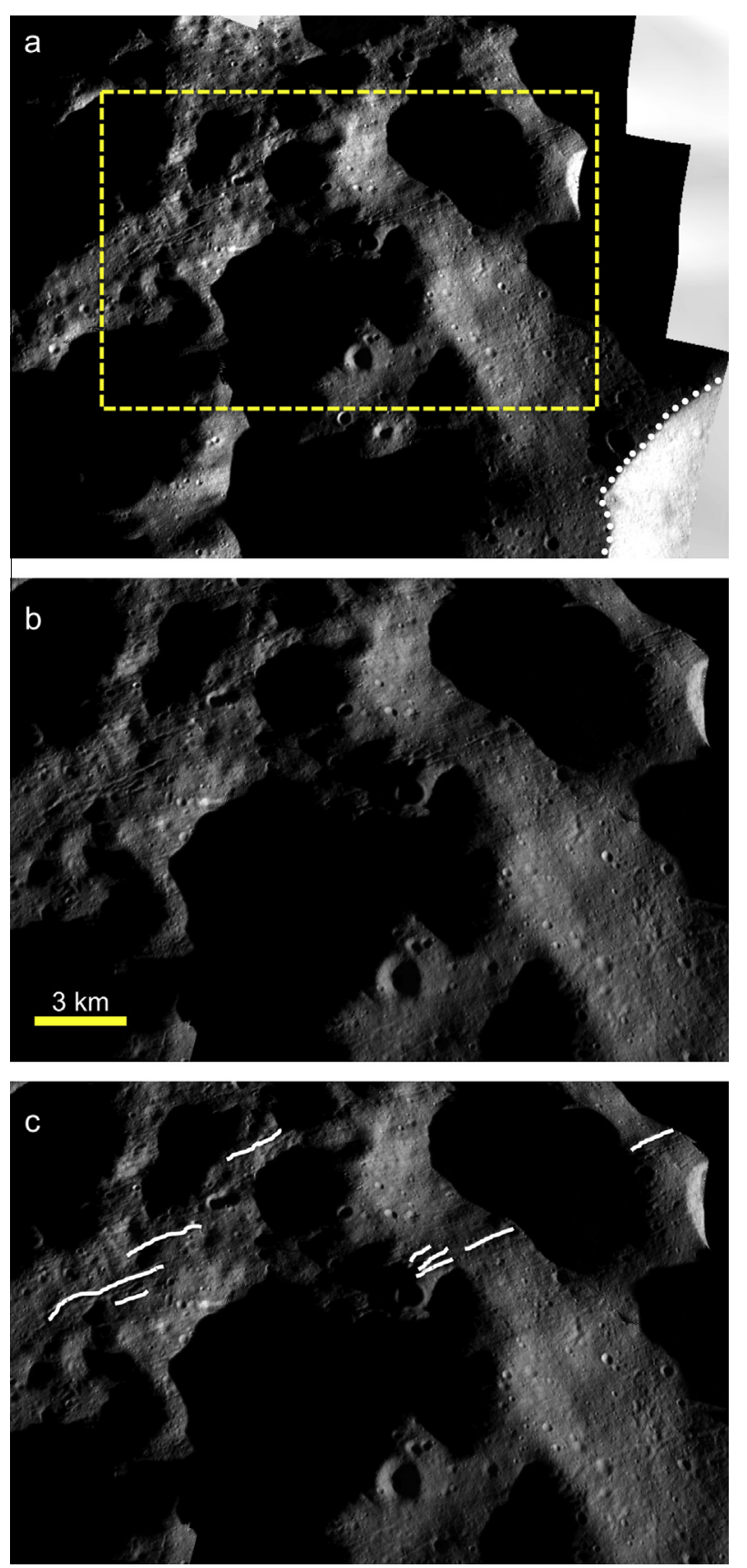

Fig. 7. Terrain exhibiting linear depressions that may be indicative of enhanced fracturing in the Av-5 quadrangle, in the area of the Veneneia antipode. (a) LAMO context mosaic centered at $\sim 53.5^{\circ} \mathrm{N}, 347^{\circ} \mathrm{E}$, refer to the area indicated in Fig. 3c. The dashed box encloses the area shown in (b and c). The dotted line in the lower right corner is the rim of the fresh crater visible to the south of the cross marking the Veneneia antipode in Fig. 3a and c. (b) Higher-resolution view of the area within the dashed box shown in (a). (c) Same image as (b), with lines mapping linear depressions that may be expressions of fractures created by the Veneneia impact event.

of Vesta's northern hemisphere indicates that the asteroid had a flattened, hydrostatic (oblate) shape at the time of the Veneneia and Rheasilvia impacts (Ermakov et al., 2014). Therefore the failure of the south polar basins to induce extensive disruption at the antipodes may be a result of such 3-D effects. On the other hand, Rheasilvia is centered quite near the south pole, and an impact on the pole of an oblate spheroid will ideally produce simultaneous seismic arrival at the antipode. Also, Meschede et al. (2011) carried out 3-D modeling of the Chicxulub impact on Earth, and found substantial antipodal deformation despite the reduction in constructive interference of seismic waves as a result of the Earth's ellipticity and lateral heterogeneity.

Second, Bowling et al. (2013) found that the extent of antipodal uplift is greatly influenced by the seismic velocity in the mantle and core even in the case of a spherical target. Thus, factors such as the porosity of Vesta's mantle and the strength of the core could be responsible for inhibiting the formation of dramatically disrupted terrain opposite the large southern basins.

\subsection{Swirl-like albedo or color anomalies}

Markings reminiscent of lunar swirls have not been recognized near the Rheasilvia or Veneneia antipodes. It must be noted however that the high-incidence-angle illumination in the Dawn image dataset for the north polar region (in particular the Rheasilvia antipode) is not favorable for detection of albedo or color anomalies. Therefore, firm conclusions following from the presence or absence of such markings cannot be drawn at this time.

\section{Discussion and conclusions}

Geologic mapping of Vesta's north polar Albana quadrangle is constrained by extensive seasonal shadows that were present during the time the Dawn spacecraft was in orbit. The limitations of the available monochrome, color and hyperspectral images prevent the geology and composition of materials present in Av-1 from being investigated to the extent possible in the other, more southerly quadrangles (Av-2 to Av-15).

The oldest unit present in Av-1 is the cratered highlands, which represents Vesta's oldest intact crust. Impact craters of sizes ranging up to that of Albana ( $~ 96 \mathrm{~km}$ diameter) are superimposed on the cratered highlands. Calculation of crater excavation depth suggests that Albana exposes material from within Vesta's crust, its depth not being great enough to reach the mantle. Albana has been heavily modified by later impacts, and does not have recognizable ejecta deposits. Several morphologically fresh craters are found in Av-1, the largest being Pomponia ( $\sim 63 \mathrm{~km}$ diameter). The ejecta from these relatively young craters is smooth and mantles the surrounding topography. The illuminated wall of Pomponia exhibits both low- and high-reflectance streaks. Elsewhere on Vesta, dark material is found both in the form of crater ejecta and in crater wall exposures. The dark material is thought to have a composition similar to that of carbonaceous chondrite meteorites, whereas bright material represents fresh, uncontaminated exposures of native vestan lithologies (Jaumann et al., 2012). A lobate deposit from wall slumping occurs on the floors of Pomponia and the smaller crater Africana. A first-order test using the Dawn global digital terrain model for Vesta indicates that the likelihood of any permanent shadow in the north polar region is small.

Terrain with a distinctive hilly and lineated morphology is found at the antipodes of large impact basins on the Moon and Mercury. Terrain of this type is absent at the antipode of Vesta's large Rheasilvia and Veneneia basins. Small structural elements in the form of linear depressions that may form by regolith drainage into fractures have been identified in the vicinity of the Rheasilvia and Veneneia antipodes. Hence these depressions may be an expression of enhanced fracturing, related to processes of the kind that are predicted by numerical impact simulations. Vesta's lack of major antipodal disruption could be a result of (a) destruction or obscuration of features by the formation of Pomponia, (b) weakened antipodal constructive interference of seismic waves caused by an oblique impact or by Vesta's non-spherical shape, or (c) attenuation of seismic waves because of the physical properties of Vesta's interior (e.g., mantle porosity, core strength). The generally elevated topography in the north polar region appears to be a 
primary characteristic of the ancient crust. Bouguer gravity mapping (Ermakov et al., 2014) suggests that at most a minor contribution to the elevated topography could result from antipodal spallation and dilation caused by the formation of the two large southern basins.

Diffuse, curvilinear albedo anomalies known as lunar swirls are found at the antipodes of many large impact basins on the Moon. Lunar swirls are correlated with regions of magnetized crust. Unfortunately, illumination conditions in the available images of the antipode of Vesta's Rheasilvia basin are not optimal for detection of albedo markings. Therefore several important questions relating to the nature of space weathering on Vesta and the role that magnetic fields may play in protecting the vestan surface from the effects of the solar wind remain open (e.g., Vernazza et al., 2006, 2009; Fu et al., 2012).

The difficulties in investigating Vesta's north polar region with Dawn imaging data emphasize the great benefits of active sensing to planetary orbital missions. While stereogrammetry and stereophotoclinometry can produce high-spatial-resolution topographic maps from images, passive imaging with visible light cannot easily map within shadows. Active sensing via laser altimetry provides topographic measurements in areas of seasonal or permanent shadow. The data can also be processed into a zero-phase albedo map (e.g., Neumann et al., 2013), offering information on the reflectance of high-latitude areas where large incidence-angle solar illumination or shadows make derivation of reflectance from standard image observations difficult or impossible. Synthetic aperture radar (e.g., Nozette et al., 2010; Spudis et al., submitted for publication) also offers a powerful means of probing the surface and near subsurface without the need for solar illumination.

\section{Acknowledgments}

The authors thank the two anonymous reviewers for suggestions that helped us to improve this paper. We thank Carolyn Ernst (JHU-APL) for discussion of crater excavation depths. We are grateful to the Dawn flight, instrument, and science teams for their efforts that led to the successful mission at Vesta and the collection and processing of the data used in this study. The work of DTB and DLB was funded by NASA Dawn at Vesta Participating Scientist Program Grant Number NNX10AR57G (DTB, Principal Investigator).

\section{References}

Archinal, B.A. et al., 2011. Report of the IAU working group on cartographic coordinates and rotational elements: 2009. Celest. Mech. Dynam. Astron. 109 (2), 101-135. http://dx.doi.org/10.1007/s10569-010-9320-4.

Belton, M.J.S. et al., 1992. Lunar impact basins and crustal heterogeneity: New western limb and far side data from Galileo. Science 255, 570-576.

Binzel, R.P., Gaffey, M.J., Thomas, P.C., Zellner, B.H., Storrs, A.D., Wells, E.N., 1997. Geologic mapping of Vesta from 1994 Hubble Space Telescope images. Icarus 128, 95-103.

Blewett, D.T., Denevi, B.W., Robinson, M.S., Ernst, C.M., Purucker, M.E. Solomon, S.C. 2010. The apparent lack of lunar-like swirls on Mercury: Implications for the formation of lunar swirls and for the agent of space weathering. Icarus 209 239-246. http://dx.doi.org/10.1016/j.icarus.2010.03.008.

Blewett, D.T., Coman, E.I., Hawke, B.R., Gillis-Davis, J.J., Purucker, M.E., Hughes, C.G. 2011. Lunar swirls: Examining crustal magnetic anomalies and space weathering trends. J. Geophys. Res. 116, E02002. http://dx.doi.org/10.1029/ 2010JE003656.

Bowling, T.J., Johnson, B.C., Ivanov, B.A., Melosh, H.J., 2012. Global resurfacing of Vesta following the Rheasilvia impact. Meteoritical Society 75th Annual Meeting. Abstract 5256.

Bowling, T.J. et al., 2013. Antipodal terrains created by the Rheasilvia impact on Asteroid 4 Vesta. J. Geophys. Res. - Planets 118. http://dx.doi.org/10.1002 jgre.20123.

Buczkowski, D.L. et al., 2012a. Large-scale troughs on Vesta: A signature of planetary tectonics. Geophys. Res. Lett. 39, L18205. http://dx.doi.org/10.1029/ 2012 GL052959.
Buczkowski, D. et al., 2012b. Analysis of the large scale troughs on Vesta and correlation to a model of giant impact into a differentiated asteroid. Geol. Soc. of America Annual Meeting. Abstract 152-4.

Croft, S.K., 1985. The scaling of complex craters. J. Geophys. Res. 90, C828-C842.

De Sanctis, M.C. et al., 2012a. Spectroscopic characterization of mineralogy and its diversity across Vesta. Science 336, 697-700.

De Sanctis, M.C. et al., 2012b. Detection of widespread hydrated materials on Vesta by the VIR imaging spectrometer on board the Dawn mission. Astrophys. J. Lett. 758, L36 (5pp). http://dx.doi.org/10.1088/2041-8205/758/2/L36.

El-Baz, F., 1972. The Alhazen to Abul Wafa swirl belt: An extensive field of lightcolored, sinuous markings. Apollo 16 Preliminary Science Report, SP-315. NASA, Washington, DC, pp. 29-93-29-97.

Ermakov, A.I., Zuber, M.T., Smith, D.E., Raymond, C.A., Fu, R.R., 2014. Modeling Vesta's internal structure with Dawn gravity and shape models. Vesta in the Light of Dawn: First Exploration of a Protoplanet in the Asteroid Belt, Lunar and Planetary Institute, Houston, Tx. Abstract no. 2019.

Ernst, C.M., Murchie, S.L., Barnouin-Jha, O.S., Robinson, M.S., Denevi, B.W., Blewett, D.T., Head, J.W., Izenberg, N.R., Solomon, S.C., 2010. Exposure of spectrally distinct material by impact craters on Mercury: Implications for global stratigraphy. Icarus 209, 210-223.

Fu, R.R. et al., 2012. An ancient core dynamo in asteroid Vesta. Science 338, 238241. http://dx.doi.org/10.1126/science.1225648.

Garrick-Bethell, I., Head III, J.W., Pieters, C.M., 2011. Spectral properties, magnetic fields, and dust transport at lunar swirls. Icarus 212, 480-492.

Gaskell, R.W. et al., 2008. Characterizing and navigating small bodies with imaging data. Meteorit. Planet. Sci. 43, 1049-1061.

Hapke, B., 2001. Space weathering from Mercury to the asteroid belt. J. Geophys. Res. 106, 10039-10073.

Holsapple, K.A., 1993. The scaling of impact processes in planetary sciences. Annu. Rev. Earth Planet. Sci. 21, 333-373.

Hood, L.L., Artemieva, N.A., 2008. Antipodal effects of lunar basin-forming impacts: Initial 3D simulations and comparisons with observations. Icarus 193, 485-502.

Hood, L.C., Richmond, N.C., Spudis, P.D., 2013. Origin of strong lunar magnetic anomalies: Further mapping and examinations of LROC imagery in regions antipodal to young large impact basins. J. Geophys. Res. 118, 1-20. http:// dx.doi.org/10.1002/jgre.20078.

Hood, L., Schubert, G., 1980. Lunar magnetic anomalies and surface optical properties. Science $208,49-51$

Hood, L., Williams, C., 1989. The lunar swirls: Distribution and possible origins. Proc. Lunar Sci. Conf. 19, 99-113.

Hughes, H.G., App, F.N., McGetchin, T.R., 1977. Global seismic effects of basinforming impacts. Phys. Earth Planet. Inter. 15, 251-263.

Jaumann, R. et al., 2012. Vesta's shape and morphology. Science 336, 687-690. http://dx.doi.org/10.1126/science.1219122.

Jutzi, M., Asphaug, E., 2011. Mega-ejecta on asteroid Vesta. Geophys. Res. Lett. 38, L01102. http://dx.doi.org/10.1029/2010GL045517.

Kahn, E.G. et al., 2011. A tool for the visualization of small body data. Lunar Planet. Sci. 42. Abstract 1618

Kattoum, Y.N., Dombard, A.J., 2009. Calculating the topography of a differentiated Vesta. Geophys. Res. Lett. 36, L24201. http://dx.doi.org/10.1029/2009GL041155.

Kramer, G.Y. et al., 2011a. Characterization of lunar swirls at Mare Ingenii: A model for space weathering at magnetic anomalies. J. Geophys. Res. 116, E04008. http://dx.doi.org/10.1029/2010JE003669.

Kramer, G.Y. et al., 2011b. M3 spectral analysis of lunar swirls and the link between optical maturation and surface hydroxyl formation at magnetic anomalies. J. Geophys. Res. 116, E00G18. http://dx.doi.org/10.1029/2010JE003729.

Krohn, K. et al., 2014. Mass movement on Vesta at steep scarps and crater rims. Icarus, this issue. http://dx.doi.org/10.1016/j.icarus.2014.03.013.

Li, J.-Y., 2012. Body-Fixed Coordinate Systems for Asteroid (4) Vesta. <http:// sbn.psi.edu/archive/dawn/fc/DWNVFC2_1A/DOCUMENT/ VESTA COORDINATES/VESTA COORDINATES 120918.PDF>.

Lin, R.P., Anderson, K.A., Hood, L., 1988. Lunar surface magnetic field concentrations antipodal to young large impact basins. Icarus 74, 529-541.

Lü, J., Sun, Y., Toksöz, M.N., Zheng, Y., Zuber, M.T., 2011. Seismic effects of the Caloris basin impact, Mercury. Planet. Space Sci. 59, 1981-1991.

Marchi, S. et al., 2012. The violent collisional history of Asteroid 4 Vesta. Science 336, 690-694. http://dx.doi.org/10.1126/science.1218757.

McCord, T.B. et al., 2012. Dark material on Vesta from the infall of carbonaceous volatile-rich material. Nature 491, 83-86. http://dx.doi.org/10.1038/ nature11561.

Meschede, M.A., Myhrvold, C.L., Tromp, J., 2011. Antipodal focusing of seismic waves due to large meteorite impacts on Earth. Geophys. J. Int 187, 529-537.

Melosh, H.J., McKinnon, W.B., 1988. The tectonics of Mercury. In: Vilas, F., Chapman, C.R., Matthews, M.S. (Eds.), Mercury. University of Arizona Press, Tucson, AZ, pp. 374-400.

Moore, H.J., Hodges, C.A., Scott, D.H., 1974. Multiringed basins illustrated by Orientale and associated features. Proc. Lunar Sci. Conf. 5, 71-100.

Murray, B.C. et al., 1974. Mercury's surface: Preliminary description and interpretation from Mariner 10 pictures. Science 185, 169-179.

Neumann, G.A. et al., 2013. Bright and dark polar deposits on Mercury: Evidence for surface volatiles. Science 339, 296-300. http://dx.doi.org/10.1126/ science. 1229764.

Nozette, S. et al., 2010. The Lunar Reconnaissance Orbiter Miniature Radio Frequency (Mini-RF) technology demonstration. Space Sci. Rev. 150, 285-302. Peterson, J.E., 1978. Antipodal effects of major basin-forming impacts on Mars. Lunar Planet. Sci. 9, 885-886. 
ARTICLE IN PRESS

10

D.T. Blewett et al./Icarus $x x x(2014) x x x-x x x$

Peters, C.M. et al., 2012. Distinctive space weathering on Vesta from regolith mixing processes. Nature 491, 79-82. http://dx.doi.org/10.1038/nature11534.

Prettyman, T.H. et al., 2012. Elemental mapping by Dawn reveals exogenic $\mathrm{H}$ in Vesta's regolith. Science 338, 242-246.

Preusker, F. et al., 2012. Topography of Vesta from Dawn FC stereo images. Lunar Planet. Sci. 43. Abstract 2012.

Raymond, C.A. et al., 2013. Vestalia Terra: An ancient mascon in the southern hemisphere of Vesta. Lunar Planet. Sci. 44. Abstract 2882.

Reddy, V. et al., 2012a. Color and albedo heterogeneity of Vesta from Dawn. Science 336, 700-704.

Redly, V. et al., 2012b. Delivery of dark material to Vesta via carbonaceous chondritic impacts. Icarus 221, 544-559.

Richmond, N.C., Hood, L.L., Mitchell, D.L., Lin, R.P., Acuña, M., Binder, A.B., 2005 Correlations between magnetic anomalies and surface geology antipodal to lunar impact basins. J. Geophys. Res. 110, E05011. http://dx.doi.org/10.1029/ 2005JE002405.

Roatsch, Th. et al., 2012. High resolution Vesta High Altitude Mapping Orbit (HAMO) atlas derived from Dawn Framing Camera images. Planet. Space Sci. 73, $283-$ 286.

Roatsch, Th. et al., 2013. High-resolution Vesta low altitude mapping orbit atlas derived from Dawn Framing Camera images. Planet. Space Sci. 85, 293-298.

Ruesch, O., Hiesinger, H., Blewett, D.T., Scaly, J., Buczkowski, D., Williams, D.A., Yingst, R.A., Russell, C.T., Raymond, C.A., 2014. Geologic map of the northern hemisphere of Vesta based on Dawn FC images. Icarus, this issue.

Russell, C.T. et al., 2004. Dawn: A journey in space and time. Planet. Space Sci. 52, 465-489.

Russell, C.T. et al., 2012. Dawn at Vesta: Testing the protoplanetary paradigm. Science 336, 684-686.

Schenk, P., 2010. Global topographic mapping Of Saturn's midsize icy satellites: System-wide thermal and impact effects. American Astronomical Society, 42nd DPS Meeting. Abstract 9.16.

Schenk, P. et al., 2012. The geologically recent giant impact basins at Vesta's south pole. Science 336, 694-697. http://dx.doi.org/10.1126/science.1223272.

Schenk, P. et al., 2013. Impact crater morphologies on Vesta in Solar System context. Lunar Planet. Sci. 44. Abstract 2039.

Schmedemann, N. et al., 2013. Lunar-like chronology for Vesta - Crater retention ages matching independent Ar-Ar HED ages, Lunar Planet. Sci. Conf. 44th. Abstract no. 2155.
Schultz, P.H., 1976. Moon Morphology. Univ. of Texas Press, Austin, TX, 626pp. Schultz, P.H., Crawford, D.A., 2011. Origin of nearside structural and geochemical anomalies on the Moon. In: Ambrose, W.A., Williams, D.A. (Eds.), Geol. Society of Am. Spec. Paper 477, pp. 141-159. http://dx.doi.org/10.1130/2011.2477(07).

Schultz, P.H., Gault, D.E., 1975. Seismic effects from major basin formation on the Moon and Mercury. Moon 12, 159-177. Schultz, P.H., Sanka, L.J., 1980. Cometary collisions with the Moon and Mercury.
Nature 284, 22-26.

Scilly, J.E.C. et al., 2014. Geomorphology and structural geology of Saturnalia Fossae and adjacent structures in the northern hemisphere of Vesta. Icarus, this issue. Sierks, H. et al., 2011. The Dawn Framing Camera. Space Sci. Rev. 163, 263-327. http://dx.doi.org/10.1007/s11214-011-9745-4.

Spudis, P.D. et al., 2013. Evidence for water ice on the Moon: Results for anomalous polar craters from the LRO Mini-RF imaging radar. J. Geophys. Res. - Planets 118, 2016-2029. http://dx.doi.org/doi:10.1002/jgre.20156.

Stuart-Alexander, D.E., 1978. Geologic map of the central far side of the Moon, Map I-1047. Misc. Investigations Ser., U.S. Geological Survey, Denver, CO.

Stubs, T.J., Wang, Y., 2012. Illumination conditions at the Asteroid 4 Vesta: Implications for the presence of water ice. Icarus 217, 272-276.

Thomas, P.C., Binzel, R.P., Gaffey, M.J., Storms, A.D., Wells, E.N., Zellner, B.H., 1997. Impact excavation on Asteroid 4 Vesta: Hubble Space Telescope results. Science 277, 1492-1495.

Vernazza, P. et al., 2006. Asteroid colors: A novel tool for magnetic field detection? The case of Vesta. Astron. Astrophys. 451, L43-L46.

Vernazza, P., Binzel, R.P., Rossi, A., Fulchignoni, M., Birlan, M., 2009. Solar wind as the origin of rapid reddening of asteroid surfaces. Nature 458, 993-995.

Whitaker, E.A., 1981. The lunar Procellarum basin. In Schultz, P.H., Merrill, R.B. (Eds.), Multi-ring Basins: Formation and Evolution; Proc. Lunar Planet. Sci. Conf., Houston, TX, November 10-12, 1980. Pergamon Press, New York and Oxford, pp. 105-111.

Wilhelms, D.E., 1987. The Geologic History of the Moon. Prof. Paper 1348. US Geological Survey, Denver, CO. 302pp.

Williams, D.A., Greeley, R., 1994. Assessment of antipodal-impact terrains on Mars. Icarus 110, 196-202.

Williams, D.A., Yingst, R.A., Garry, W.B., 2014. Introduction: The geologic mapping of Vesta. Icarus, this issue.

Yingst, R.A. et al., 2014. Geologic mapping of Vesta. Planet. Space Sci., in press. http://dx.doi.org/10.1016/j.pss.2013.12.014.

Please cite this article in press as: Blewett, D.T., et al. Vesta's north pole quadrangle Av-1 (Albania): Geologic map and the nature of the south polar basin

antipodes. Icarus (2014), http://dx.doi.org/10.1016/j.icarus.2014.03.007 